\title{
Fantasy is More Believable: The Shadow Civil Sphere in Chinese Online Fiction'1
}

\author{
Xiaoli Tian \\ Department of Sociology \\ The University of Hong Kong
}

For citation:

Tian, Xiaoli. 2019. "Fantasy is More Believable: The Shadow Civil Sphere in Chinese Online Fiction.” Pp. 167-187 in The Civil Sphere in East Asia. Edited by Jeffrey Alexander, David Palmer, Sunwoong Park and Agnes Shuk-mei Ku. Cambridge: Cambridge University Press.

\begin{abstract}
:
Using online fiction in China, this chapter explores whether there is still space to express civil values in a "subjective" civil sphere when that civil sphere lacks institutionally protected legal and communicative spaces. Based on online observations, interviews with online fiction writers and readers, and content analysis of selected popular works of online fiction, I argue that online fiction has created survivalist and revenge-themed fantasy worlds that act as a shadow civil sphere. On the one hand, shadow refers to the dark side of the civil sphere wherein people use extremely anti-civil online fictions to reject the empty moral values promoted by the state. On the other hand, in the shadow people are still expressing moral ideals through cynicism. By creating a fantasy world that's more nasty and brutish than reality, they are expressing their cynicism regarding the society, the social system and the pretense of the public world. However, their cynicism actually articulates their belief in those civil values.
\end{abstract}

Keywords: online literature, fantasy, subjective civil sphere, internet, China

\footnotetext{
${ }^{1}$ I thank Jack Barbalet, Paul Joosse, Liping Wang and the editors of this volume for their helpful comments on early versions of this chapter.
} 
Civil sphere theory (Alexander 2006) reconceptualizes the cultural and institutional foundations of democratic life. To understanding how real individuals live together in real societies, the theory emphasizes solidarity and community, namely feeling for others, rather than self-interest or domination (power) over others. The core of the civil sphere is binary codes that structure the meaning system of all of the actors because they define the purifying or polluting qualities of motives and social relations. This symbolic tradition is deeply felt and shared by all group members as a universalistic script, which provides important recourse for criticism and civil repair. Therefore, culture and communication play important roles in the struggle for justice.

A civil sphere comprises civil discourse and institutions, such as electoral and legal regulations. Communicative and regulatory institutions support and nurture a civil sphere. Communicative institutions particularly sustain the civil sphere because the civil sphere requires civil discourse and the ability of individuals to speak a civil language, in which the principles of equality and justice are essential values. Therefore, communicative institutions mediate the underlying language of democracy. The mass media, such as the internet, broadcast and articulate the imagined and idealized civil domain, and most importantly, allow familiarity with the civil discourse.

Civil society discourse is important because learning how to speak civil society language and committing to democratic values make democratic social life possible. In Western societies, this discourse is learned through socialization, non-educational discourses, and institutions. As such, the mass media, including "factual" (journalism, news media) and "fictional" (novels, television shows, or movies) mass media (Alexander 2006, Chapter 5), is an essential component. While the factual mass media records, selects, and reconstructs societal events, 
fictional media to some extent removes one from the immediate social realities, and can therefore create frames for understanding what is constituted as civil or uncivil. Consequently, when the civil spirit is challenged in real social life, the fictional media tends to provide cathartic relief (Alexander 2006, p. 76).

While civil sphere theory was developed for the Western context and is framed within the context of democracy, it was also meant to be applied beyond the West. But how can civil sphere theory relate to a non-democratic society? Alexander (2015) argued that civil spheres not only exist in well-developed democratic modern societies, but also in modernizing societies (p. 173). Moreover, "partial" civil spheres exist in societies that have yet to be formally democratized (Alexander 2015). As Khoshrokovar (2015, p. 153) pointed out, "a full-fledged civil sphere does not actually exist in every society, but the capacity to build one is inherent at least to every modernizing society, and can be actualized". When no civil sphere objectively exists in civil institutions, there can be instead, a subjective civil sphere, or one of the mind (Khoshrokovar 2015, p. 173-174).

Yet without the objective elements of a civil sphere, the civil institutions and the discourse that nurture and support the civil sphere, can there be any civil spirit? Since a civil sphere provides institutionally protected legal and communicative spaces for the expression and enactment of civil values based on moral codes, is there still space to elaborate or express civil values in a "virtual" or "subjective" civil sphere without institutional protection? Where does the capacity to build a civil sphere come from?

Online fiction in China is an excellent case to examine these questions, given the incredibly high levels of readership and even mass participation in the formulation of stories. Yet can online fantasy compensate for the limited space where people can voice criticisms to a 
listening audience in real life in China? When more established communicative institutions and regulatory institutions are not permitted to function as those of a civil sphere, can literary websites as fictional new media help to construct a "subjective civil sphere"? That is, when no channels exist in public life for open expressions or criticisms, can the subjective civil sphere be pursued through a fantasy?

In this chapter, I explore the possibility of a subjective civil sphere via fiction on new media in an authoritarian society with little opportunity for citizens to freely express themselves in public life. In a politically repressive, market-saturated society without autonomous communicative institutions and electoral and legal regulations, literary websites are a relatively open communicative institution with little regard for state control because of their literary characteristics (Yang 2008). Chinese society stresses individual efforts and success in a market economy, but in an increasingly crystalized class structure in which social justice is difficult to achieve. As such, I argue that Chinese readers turn to the fantasy worlds of online fiction that are saturated with the two main themes of survival and revenge. In doing so, the Chinese users of literary websites have created a shadow civil sphere.

Shadow civil sphere means two things. On the one hand, the shadow means the opposite or the dark side of the civil sphere. People are rejecting the empty moral values as promoted by the state with extremely anti-civil online fiction. On the other hand, in the shadow people are still expressing moral ideals through cynicism. By creating a fantasy world that's even more nasty and brutish than real society, they are expressing their cynicism in regards to the society, the social system, and the pretense of the public world. However, this cynicism actually articulates their belief in those civil values. The very fact that people favor fantasy fiction reflects their disappointment with reality and their desire for an ideal society. 
Others may be relatively optimistic about the subjective civil sphere, such as Khoshrokovar (2015) who refers to the Arab Spring and the 1989 uprisings against state tyranny. However, I am much less idealistic and show that in an extremely anti-civil society, the subjective or imagined world is not utopic but dystopic especially for the less privileged and oppressed, which reflect the realities of the authoritarian state in China with a long history of an imperial past. In so doing, I contribute to civil sphere theory by showing how subjectivities respond to the absence of civility in the social structure.

In the following, I will first briefly review the popularity of online fictions in China. After providing the data source and method, I will outline the main narrative patterns in popular online fantasy fictions, and decipher their underlying moral codes. I will then turn to the origins of the fiction itself, describing how the inherent values reflect the daily realities of ordinary Chinese citizens. I conclude by discussing the implications for understanding the future of the civil sphere in China.

\section{The Empirical Case}

In 2017, a TV series entitled San Sheng San Shi, Shi Li Tao Hua (Eternal Love) achieved a milestone in viewership, with over 30 billion hits online. In related discussions on social media, one of the most popular topics revolved around the heroine who suffered much abuse from others. Many hoped that she would jump off the "celestial execution platform" to not only end her current life and the abuse, but return as a powerful immortal and enact revenge. "SuSu (the 
heroine) jumping off the celestial execution platform" was a popular online search topic with 890 million views and 1.27 million discussions in two months. ${ }^{2}$

Adapted from a renowned online novel like many other popular TV series and movies, Eternal Love is an example of the vibrant and curious development of online literature in China that began in the 1990s. As of June 2017, around 46.9 percent or 352 million $^{3}$ (CNNIC 2017) internet users in China read online literature. A 2010 survey showed that 20 million users have published original works online, and 2 million are registered writers on online literature sites. Online literature sites receive over one billion visits daily, and the users continue to increase in number (CNNIC 2010).

Although online literature ${ }^{4}$ is found in Western countries (Bootz 2011), such as fan fiction, China is comparatively unique due to the large volume of works produced and the extremely rapid pace of development. Online literature in the West is mostly a sub-cultural side hobby with a specific audience and little cultural impact, but in China, it attracts a large proportion of the total population, and is a very mainstream culture (CNNIC 2010). Thus, online literature has become one of the main driving forces of the cultural and creative industries, such that for instance, even video games have drawn inspiration from them (CNNIC 2010), and numerous online fiction works have been published in print and adapted for film and TV recently, further increasing its social impact (Cui 2011; Li 2012).

\footnotetext{
${ }^{2}$ From February 9 to April 9, 2017, with the majority of the views in February (http://www.weibo.com/p/1008080dba0e8f597159bfb918758bf74a91b4).

${ }^{3}$ The most recent CNNIC report also shows that mobile online literature users are increasing in China. As of June 2017, 326 million users read online literature through their mobile phone, or around $45.1 \%$ of all mobile internet users.

${ }^{4}$ In the paper, online literature is defined as writings that are originally produced and published for readers on literary websites to view and circulate. It includes "fan fiction", where people develop their own versions/accounts of stories by professional writers. However, the vast majority of online fiction in China is not fan fiction. For more details on the history and features of online fiction in China, see Tian and Adorjan (2016).
} 
Moreover, the genres and content have distinct characteristics. In North America, online literature writers often focus on using experimental hypertext (stories with unconventional text), such as works composed with multi-media content (Rau 2001; Torres 2005; Ryan 2011), whereas the focus in China is on fiction with conventional linear narratives. In fact, online fiction (wang luo xiao shuo) has such a powerful presence that it is considered synonymous to online literature (wang luo wen xue). ${ }^{5}$

Consequently, this commissioned production has resulted in the stylizing of Chinese online fiction (Tian and Adorjan 2016); that is, there are very few specific genres. The most popular genres are xuan huan (fantasy adventures based on traditional Chinese mythology), chuan yue (time-travel historical romance), and qi huan (fantasy adventures based on Western mythology) (Xiang and Montgomery 2012). For example, the largest literary website, Qidian Zhongwenwang, categorizes 559,692 fictions as xuan huan, which is the most popular genre. ${ }^{6}$ Also, nine of the top ten subscribed online fiction works are a fantasy genre. ${ }^{7}$ The degree that the fictional worlds differ from the real world characterizes them as either high or low fantasy (Frye 1973), with the latter dominating (Shao 2016).

"The fantastical" is thus an important feature so that stories are often situated in supernatural worlds in which the characters can travel in time, are reborn, become immortal and have super powers. For example, the 800 chapter long Pan Long (Coiling Dragon, published in hard copy in 2013) featured the adventures of young protagonists in a continent of saints and

\footnotetext{
${ }^{5}$ In earlier years, such as the 1990 s, online literature had different formats, such as poetry. However, starting from the mid-2000s, all other forms became so marginalized that online fiction has become synonymous with online literature.

${ }^{6}$ Only fiction published on Qidian since June 2011.

${ }^{7}$ Source: www.qidianshuju.com/rank/101/0.html
} 
immortal beings of unimaginable power. Bu Bu Jing Xin (Startling by Each Step), the most popular time travel historical romance, featured a modern woman who travels back through time and falls in love with prominent historical figures.

This curious phenomenon in China has significant sociological implications. The sociology of literature has long indicated that the composition of the readership/authorship, and the form and content of fiction might reflect important information about the context itself (Griswold 1993). Why is Chinese online fiction dominated by high fantasy? How, in particular, is online fiction related to the daily life of the literary website users, who are situated in a wider market economy in authoritarian post-reform China?

\section{Data and Method}

To answer these questions, data were collected through online observations on two of the largest Chinese literary websites (Qidian Zhongwenwang www.qidian.com and Jinjiang Wenxuecheng $h t t p: / / w w w . j j w x c . n e t /)$, as well as in-depth face-to-face interviews with 8 writers and 31 readers of various social backgrounds. Interviewees were solicited through a literary website platform and recruited offline through a snowball process to understand why they write or read online fiction. Their household monthly income ranged from 5,000 to 40,000 RMB (around 725 to 5,788 USD). Interviews were conducted during research trips to seven Chinese cities, including Beijing, Shanghai, Guangzhou, Shenzhen, Hangzhou, Wuhan and Changsha, for a better understanding of the exact social and psychological factors at work when individuals write or read online fiction. For readers, I asked about both their online and offline experiences, focusing on why they read online fiction and how it is different from popular fiction written by 
conventional writers (such as Jin Yong and Qiong Yao). For the writers, I concentrated on why they spend time writing fiction online.

I focused on online fantasy fictions and identified some for a detailed content analysis because they are the most influential and frequently mentioned during the interviews. They are: The Attack of Heaven ${ }^{8}$, followed by Eternal Love ${ }^{9}$, The Journey of Flower ${ }^{10}$, Startling by Each Step $^{11}$, A Record of a Mortal's Journey to Immortality ${ }^{12}$, and Battle Through the Heaven ${ }^{13}$, among others. In the following, I address the thematic content of online fiction, the contemporary social situation, emotional-moral motives, and concrete interactive experiences.

\section{Thematic content of online fiction in China}

The content analysis showed that popular online fiction, situated in an imaginary world with feudal hierarchies and magical powers, emphasizes enhanced personal abilities and achievements to survive in a ruthless world as well as acts of retaliation in a Hobbesian state of nature, i.e. battles are personal and individual, and therefore not mediated by appeals to any external authority for justice.

\section{Becoming the greatest just to survive}

In the most popular online fictions, the male hero is often ordinary yet impoverished, and then, progressively achieves victories and rises to the top. This is the storyline of The Attack of Heaven, which started online in 2003 and was published in print in 2006. The main protagonist is an orphan with very ordinary looks and qualifications. He navigates through a series of

\footnotetext{
8 诛仙 https://www.kanunu8.com/files/yuanchuang/201102/1530.html, original link on hjsm.tom.com is no longer available.

9 三生三世, 十里桃花 https://www.kanunu8.com/files/yqxs/201104/2460.html, original link on jjwxc.net locked

10 花千骨 http://www.jjwxc.net/onebook.php?novelid=316358

11 步步惊心 https://www.kanunu8.com/files/yuanchuang/201102/1416.html, original link on jjwxc.net locked

12 凡人修仙传 https://book.qidian.com/info/107580

13 斗破苍穹 https://book.qidian.com/info/1209977
} 
challenges and adventures in a world full of immortals and chivalrous swordsmen to reach his final victory. During the process, he is often mistreated and fends for himself, and his perils are likened to "One person with a stove poker, facing the entire world" (Book 1, Chapter 26, p. 173). The bootstrap rhetoric is again signaled by questions such as "What is true righteousness?", but the only response seems to be that the "Heartless World treat[s] everything like straw dogs!" (for example, Book 1, Chapter 3, p. 14).

Of course, "becoming the greatest" is an old theme. However, online fiction heroes are very different from conventional fiction heroes, such as those in martial arts fiction written by Jin Yong. ${ }^{14}$ Both in the East and West, conventional superheroes have been saving or bettering the world. Personal survival is not their concern. Yet it is key in online fiction. In contrast to the morally superior "good guy heroes" with superpowers, in online fiction, these "ordinary guy heroes" have no moral restrictions, goals or obligations, and strong-willed "bad guy heroes" with selfish intentions are ubiquitous. Because their utmost goal is to become stronger in order to survive, their personal agenda even justifies immoral deeds.

In terms of morality, online fiction is also radically different from earlier generations of folk literature. In the classic fiction, Water Margin (水吘传) for example, the protagonists are bandits and yet they still harbor a strong sense of "righteousness"(义气) that allows them to justify their many anti-civil actions. But the anti-civility in this online fantasy world goes further than in feudal. There's no underground opposition, and since only the imperial center still has power, each individual must fend for himself or herself. In Palmer's chapter in this book, he distinguishes three moral codes in contemporary Chinese society: yellow codes are derived from

\footnotetext{
${ }^{14}$ Jin Yong (b. 1924, a.k.a Louis Cha, co-founder of the Hong Kong daily newspaper Ming Pao), is the best-selling Chinese author alive, with over 100 million books sold. He has been canonized as the master of martial arts fiction.
} 
Chinese traditional values (Confucian values as the main components), blue codes are derived from Western liberal values, and red codes are from China's revolutionary tradition. Here, the online fictions draw from Chinese traditional values, or, yellow codes. But the level of corruption or the weakening of the civil norms of the Confucian code is much deeper than any previous forms of representation.

By contrast, online fictions target female readers with stories of pure or endless unconditional love. The female protagonist is often deeply loved by many high caliber men who are willing to die for her. One example is Eternal Love, which started online in 2008, and was published in 2009. This fantasy romance details the love affair between the royals of two tribes Bai Qian, the High Goddess of the Nine-tailed Fox Tribe, and Ye Hua, the Crown Prince of the Celestial Tribe. Their love spans three reincarnated lives, yet Ye Hua never stops loving Bai Qian, even though at one point she had forgotten him for over three hundred years.

While unconditional love is also not a new theme, online fiction is different because it values self-reliance and survival rather than morality. The romance novels by Qiong Yao ${ }^{15}$ feature strongly moralizing narratives. For example, lovers can overcome obstacles (often due to different social classes) only if the authorities (parents, superiors) are moved by their pure love, whereas in online fiction, female protagonists rely on themselves to overcome obstacles after gaining strength and wisdom. Moral values now comprise obstacles that thwart desires (e.g., the love of a man). In fact, moral characters in online fiction are denounced through disparaging labels such as "Virgin Mary Bitch" (women who appear to be morally superior and genuinely caring).

\footnotetext{
15 The most popular Taiwanese romance writer; many of her works have been adapted into movies and TV series, and are influential in both Taiwan and mainland China.
} 
This cynicism is prevalent in works that target both men and women. The protagonists have no idealism, values, or moral principles. For example, they are indifferent even if others need to die for their own power to be preserved. These and similar storylines are very common and readers support and even anticipate them. For example, the female protagonist in Zhen Huan Zhuan (Empresses in the Palace) originally strived to merely survive as a concubine, but after much abuse from the Empress and other concubines, she used cunning schemes to kill some of her former competitors, drive others mad and forever imprison others. The online audience applauded her ruthlessness. The male protagonist in The Attack of Heaven even joined the devil's cult and justified murders, including innocent people, as a means of survival, which the interviewed readers considered to be legitimate. Therefore, these fantasy fictions reflect a world of ruthless competition in which individual strength and achievements are priorities. The main protagonists often resort to dishonorable deeds, which leads to the common sentiment that survival means sacrificing human dignity or morality.

\section{Revenge in the state of nature}

Revenge is another running theme, characterized by retaliation in that after the hero(ine) becomes more powerful, s/he retaliates through his/her own means, rather than legal institutions or external authorities for justice. Here, justice means getting revenge, and retaliating by taking matters into one's own hands, often through dishonorable tactics, but the readers do not respect him/her any less. The legitimacy of revenge is never questioned. For example, many online commenters of Eternal Love anticipated the part where the female protagonist, SuSu, jumps to her death, is reborn and returns to take revenge. Thus, the hero(ine)s get justice in the state of nature as discussed by Hobbes ([1651]1994), in which every human has the natural right or the 
liberty to do anything considered necessary to preserve one's own self-interest without interference from the external powers to keep foes in awe.

\section{Fantasy is more believable}

When asked why online fiction usually takes place in a fantasy world, many of the respondents indicated that a story set in real life nullifies the credibility of the story itself and the characters, who are therefore not relatable. A fantasy setting is more convincing, and allows engagement with the storyline and a high level of identification with ease. The imagined worlds, with emphases on survival and revenge, reflect what is considered to be the realms of justice or fairness in real social life, and are related to the social realities in contemporary China.

\section{Getting ahead in an increasingly fixed class hierarchy}

The hero's rise parallels upward mobility in an increasingly fixed class hierarchy. In fact, this is a popular storyline because upward mobility is very difficult to achieve in real life, especially for underprivileged groups. Personal struggles are recognized in online fiction because in reality, personal ability contributes little to upwards advancement. As an auto factory worker said:

A low class guy like me with no money becoming a rich man won't ever happen in real life. But it would happen in the fantasy world... you could meet someone who guided you...Or...you have superpowers... In real life, say that someone like me, a worker, becomes the president of my company...it's never going to happen...nobody will believe that kind of story. (Interview 35, male, 30, Shenzhen) 
Similarly, others also frequently measured plausibility with current social issues in China such as the crystallization of social class divisions. They confessed that their fondness for online fiction is really about "becoming the greatest" to fulfill desires that are difficult to realize in real life.

...(T)hings are so hard... [in] our parents' generation, as long as you work and are willing to work hard, then...there's the opportunity to succeed. But not now...the gap between the rich and poor is too big and the rich only get richer. Guanxi ${ }^{16}$ matters so much. People with guanxi don't have to do anything, but get more than any of us who work really hard. (Interview 11, female, 29, Guangzhou)

The respondents often cited relationships that involve patrons and the gap between the rich and poor. Actually, the former merely reinforce the ever-widening gap between the rich and poor. In contemporary China, the market economy now dominates many aspects of daily life; economic capital is now the foremost criterion of social status. Being shut out of upward mobility lead respondents to feel stagnant, especially since there is no channel in public life to freely express the underlying sense of deprivation or unfairness. Desperation then leads to solace in the fictional worlds online, where readers flock to satisfy their craving for advancement. ${ }^{17}$ The language of justice in online fiction is in fact a response to the experiences of living in a strong market economy with strong state control. The need to compete and excel over others is thwarted by the lack of equal opportunity or control over any of the societal structural elements.

\section{Personal revenge and skepticism about the rule of law}

\footnotetext{
${ }^{16}$ Chinese term for social relationships or social connections usually relate to favors that involve a patron.

${ }^{17}$ It might not be a coincidence that online fiction became a widely noticed phenomenon after the 2008 financial crisis.
} 
The reason that viewers celebrate ruthless revenge storylines is explained by a study respondent:

Why are we all waiting for SuSu (the mortal identity of Bai Qian, Goddess of the Ninetailed Fox Tribe) to turn back into Bai Qian? It's probably because we too yearn and desire for vengeance in our heart. (Interview 20, female, 34, Hangzhou)

Thus, revenge stories widely appeal to Chinese readers because they personally identify with the strong emotions derived from the desire for revenge. This affinity was also mentioned by another audience member:

When we're at work, our boss yells at us, but we don't talk back. When we're at home, our in-laws and husband bully us... we can't ...talk back... So...we watch TV and see that Bai Qian...gets her revenge, and we feel how good it is to seek vengeance too. (Interview 23, female, 37, Beijing)

Here, the readers might be favoring revenge stories as a reflection of negative feelings towards material conditions and social inequalities (Ngai 2007). Those feelings can also be a form of opposition to the current social and political orders.

When asked why revenge always happens in the state of nature in online fiction, the readers pointed out that people do not trust the rule of law, nor do they want a law-based society, because they have never benefited from one. Disappointment with the current legal system in China means that matters are taken into one's own hands.

The antagonists in the novel are all evil, which makes us want to kill them. In reality, even if someone is evil, and handed over to the law for punishment, he doesn't necessarily have to die. As long as you have the right connections, a death sentence can change into life imprisonment...In online fiction, you judge the bad guys and take 
revenge. It's psychologically satisfying as the bad guy gets what's coming to him. (Interview 13, male, 29, Shanghai)

The overwhelming amount of unfair issues in contemporary Chinese society means that many, including the study respondents, do not believe that the law can bring justice to society.

The girl who travelled to Lijiang in Yunnan, for example. She was beaten by several men. But the police didn't even build a case for her.... So I don't trust the police, nor the law... when I read about revenge in online fiction, I feel so happy that they (the characters) are able to do what we can't in real life. (Interview 6, female, 31, Wuhan)

Another respondent cited a recent example to illustrate the unfairness of the legal system in contemporary China:

...The law... only helps those who are rich or powerful...It's like that official who ate the pangolin. Nothing happened to him...he only got suspended... But the Henan university student got 10 years for hunting birds... That's social injustice...the laws of China protect the rich and powerful...(and not) those who are poor and it certainly doesn't favor you. On the surface..."everyone is equal before the law", but in reality, this isn't true.... (Interview 30, male, 25, Shenzhen)

Since the formal and institutionalized channels in the real world do not provide justice, characters seeking justice in online fiction never resort to the law. Rather, it is more desirable and realistic to rely on personal acts for justice, which reflects readers' discontent with the current social order and their distrust of the legal system in China.

\section{No outlet for protests and social changes}

The construction of fantasy is also related to the lack of civil repair in contemporary China. Following the discussion on revenge and justice, I asked the respondents if they have 
attempted or considered making structural changes, such as changing rules (major or minor) that influence their life through personal or collective efforts. They have not and believe that it is futile:

I dreamed about changing the world. For example, doing something for my city and my hometown...But now I realize that I'll never make a difference... (Interview 12, male, 37 , Shenzhen)

Many of the respondents shared the sentiment that the government could be oppressive and restrictive, but they cannot change the situation without becoming a part of the existing forces of power. Even though there are many protests in China, the state usually pacifies the protesters so that protests do not change the structure or the system (Lee and Zhang 2013).The interviewees admit that online fiction is appealing because there is lack of options or control over their own life or the related changes. Therefore, fantasies are an outlet due to the lack of options for civil repair in real life.

\section{Limited imagination in non-democratic communicative institutions}

Interestingly, despite powerful, attractive and wise female protagonists, the fictional worlds still feature strong gender inequality usually in a polygamist society in which men have multiple wives. Similarly, in his quest to "become the greatest", the male protagonist solely focuses on his own survival and rewards, but never tries to make the fictional society more equal and just.

One can theoretically fictionalize any world, but Chinese fantasy fictions are reminiscent of Chinese imperial society. For example, in the time travel fiction, no one has ever gone back and built a society like the Roman republican system, or changed the political structure. Even if 
this person became royalty, there are no elections or other democratic elements because the rule of law and democracy are not appreciated nor coveted. Thus, imperial power rules the imagined world, rather than an equal and free democratic society because:

This is...Chinese history. China has always been a hierarchical society with an emperor. Online fiction has to be based on something familiar. We don't know much about the political systems in countries like the USA... so it's hard to convince readers that those political systems could be possible... (Interview 36, female, 29, Shenzhen)

While Chinese readers are unsatisfied with the current social system and fantasize about something different, they draw on and identify with Chinese imperial history, a most convenient cultural resource. Confucianism is not democratic. But it is also an anti- Hobbesian order. It is the best social order that the readers and writers can fathom. Confucianism allows adjustments and has its own understandings and ways of achieving social justice. Therefore, it is certainly a better option than the current chaos in a transitional society.

Another respondent explained why the online fantasy worlds are still hierarchical rather than egalitarian:

Many readers...don't want an equal society. You want to be the center of the world. Why would you want equality? You want to be the most powerful, so others are afraid of you. (Interview 37, male, 25, Wuhan)

Therefore, the Chinese perception of social order is still very influenced by its Confucian and imperial past which emphasizes social hierarchy. As China moves towards a market-economy that encourages competition, people become even more invested in the idea of status and social hierarchy. 
The online fiction storylines reflect the current social situations in China, a society without an actual civil sphere. Contemporary Chinese society is an extremely competitive, profitdriven and ruthless market society with a very small safety net and increasingly fixed class hierarchies. Justice cannot be realized through social movements in the face of strong state dictatorship. Even worse, the so-called "democratic" institutions are organized from top-down without rights. They thus eliminate the possibility of exercising civil rights in speech or legal access, and cripple imagination with the few permissible cultural recourses.

In its obsession with supremacy, eternity, pure love and justice, this fantasy world is underpinned by a Confucian social order and some Confucian moral codes, such as hierarchical social order. And yet, some of the most civil parts of the Confucian code, such as righteousness and man of virtue, are actually weakened or even non-existent. By questioning and even ridiculing some key elements, online fictions, one could say, corrupt and distort the Confucian code of civility.

\section{Cathartic effects of online fiction}

The respondents fantasized about being more powerful in real life, as many repeatedly expressed feelings of powerlessness, lack of control, uncertainty, anxiety, and repression, especially those who experience high levels of stress in daily life and work, for example, migrant workers. Online fiction rouses ecstatic or elated feelings, so that they can temporarily forget about their situation.

This escapism has cathartic effects as many of the respondents take comfort in the virtual fulfillment of their desires: supremacy, eternity, pure love, and justice, and feel psychologically satisfied when the antagonist is punished, inequality is rectified, and the underdog becomes the 
hero. These reflect the substantial pressure that they face in real life, and thus the remedy that alleviates psychological pressure and anxiety. Even the repetitive and stylistic characteristics and extremely long length (usually several million words) of the fictions do not deter them:

I already have so much stress...I'm verbally abused by my boss...can't afford an apartment. If fiction is about these things, I'd feel even more depressed.... So when I read online fiction...I hope things will go the way I want...which means that the stories and plots are similar. But it doesn't matter. I still want that. (Interview 28, male, 34, Beijing)

An interviewed migrant worker said that poor treatment from bank tellers and government officials because of his lower social class status causes feelings of worthlessness and loss of dignity on a daily basis. He reconciled these indignities by reading fiction online, so that he could imagine being successful and strong enough to seek vengeance against those who think so little of him.

When asked whether there are any similarities or differences between the fantasy and real worlds, a respondent said:

The emphasis on money, power and status is the same. Even in xuanhua fiction, there is a heavenly emperor, just like the emperor on earth. This is power. Everyone has to kneel in front of him. We too have to lower our heads in front of the powerful. The emphasis on social relationships and birth and family status is very similar. The difference is that the online worlds are so ideal. You get everything you want...(Interview 4, male, 29, Beijing)

Thus, there is no question that fantasy is an escape due to lack of power, and compensates for living in an authoritarian state. This echoes the existing academic literature according to 
which, when faced with overly-constraining social realities, people strive for a means to demonstrate control or mastery (Hirschman 1983; Hill et al. 2012).

While these feelings of desperation and expressions of frustration are most strongly expressed by the underclass, especially migrant workers, they are actually also prevalent among other social groups. Middle-class interviewees, including university teachers, and white collar workers, often felt degraded in a lawless society with little room for civility or justice. When equality is scant, they also need to lower themselves socially to appease those who are higher on the social hierarchy. They feel injustice because those who are higher in the hierarchy did not get there based on their own merits. Most importantly, they are also disillusioned of any social change or improvement. In fact, some have tried previously but in vain. When society lacks basic civility and mutual respect between different social groups, inter-personal conflicts are common in day-to-day life. Frustrations accumulate simply from social contact. These conflicts are tiring

and degrading, leading to despondence and misery. They compel the desire for a better society, if just to preserve basic human dignity. Thus, the non-civil society causes desperation, anxiety, pain, and frustration that beg for emotional release, restoration of dignity and a sense of fairness, which are realized by reading fantasies.

\section{Solidarity in online community}

Another primary reason that readers enjoy online fiction is the interaction process with writers and other readers. In China, online literature is a commercialized for-profit industry. To maximize profits, the websites have various features that encourage engagement, thus resulting in continual interaction with writers and other readers. For instance, readers can encourage writers to more frequently update their story by sending monetary incentives, such as purchasing access to stories. The literary websites also allow readers to support their favorite writer or 
fiction through rankings (Tian and Adorjan 2016). Tian and Adorjan (2016) found that these characteristics draw writers and readers into a dynamic power relationship in which writers are worshipped by their readers, yet also pressured to appease them. This is dubbed "commissioned production" to highlight the sponsorship role of some of the readers who pay particular writers for story updates. In addition to their love for the stories, readers are thus drawn to online fiction because the reading process gives them the power to influence both the development and fate of the story (Tian and Adorjan 2016).

Since the internet makes spontaneous participation and instant feedback possible, readers can now easily form a group of networked audience. For example, they can leave their posts and comments below the text of the web fiction, form chat groups, and open new topics to discuss plots of the novels or their favorite characters on online platforms. Thus, readers and writers, and readers amongst themselves, bond to form a close-knitted virtual community.

The readers follow updates to the fictions regularly on literary websites. They often refer to the writers as if they are celebrities, and address them as "Dada" (literally meaning "big big"), which is a childish word for "father"/ "uncle"/"the eldest" in Chinese. Every day, they wait earnestly for updates, and are grateful for the efforts of the writers. As it takes a fairly long time to write fiction, readers often develop very strong emotional ties with the writer, and many become well acquainted.

Being now much more networked online than offline, readers and writers can achieve collective creations based on their imagination and connect with those who have similar worldviews and values. They form unique communities of their own online and manage to exert greater influence and have more say in the interaction with the author. Feedback from readers 
can significantly influence the writer, so it has become very common for writers to take the opinions of their readers into account when deciding on the plot and fates of the primary characters in their fiction.

The prolonged interaction between readers and authors and among readers themselves transforms fictional figures into formulaic persona with a rather consistent personality across a large number of fictions (Tian 2016). It is a process where producers and readers work together on the internet to reach consensus on how to position and construct the fictional characters in the imagined world of online literature. As a result, the persona is often infused with their shared opinions, beliefs and ideologies. Thus, new potential social norms or forms of morality may emerge through these online discussions.

Also, the congregation of readers forms a strong virtual online community, which produces comradery because other readers also experience alienation in the present society, and are also seeking an alternative society in the fantasy world. Solidarity is also realized when commonly held group values are strengthened, especially those that are difficult to socially realize in real life such as fairness, and the appropriate reward is given for certain characteristics and emotions, such as loyalty and love. Readers also experience freedom and liberty (although usually through selfishness and nihilism), which are entirely absent from the political realm of contemporary China. In this sense, the readers and writers of online fiction create a micro civil sphere, but no more and no less than zillions of other forms of micro civil spheres in China (see also Palmer's chapter in this book).

\section{Shadow civil sphere}


Given its limited emphasis on political systems and focus on individual success, online fiction rarely develops the civil spirit, especially when compared to the core values of the civil sphere (Alexander 2006). Chinese online fiction is undeniably saturated with anti-civil values: extreme individualism, revenge as justice, ruthlessness, dishonorable deeds, narcissism, fantasies of total love and total domination and subjection, the need for absolute purity, and a Hobbesian vision of society. Rules or the current social order are considered to be constraints. When "I" become stronger, I can survive and do not have to be constrained by the rules anymore. However, everyone else is still subjected to those rules, whether they are fair or not. The focus is on how an individual performs, and as for the laws of the world, they are already in place and changes cannot be made. You can only change yourself. In this sense, the key features of the civil sphere, such as caring about others and universalistic solidarity, still have a long way to go in China.

Fantasy fiction writers have clearly not created a democratic world in their stories because they never engage in social critique, or depict societies that have some civil qualities. This is not surprising because as social actors, how Chinese online literature users understand civil, uncivil, and moral virtues is constrained by the particular time and place in which they are embedded. Below is a summary of how the core Western democratic civil values (blue codes) are merited in Chinese online fiction.

\begin{tabular}{|l|l|}
\hline Core civil values (as in blue code) & Merit in Chinese online fiction \\
\hline Justice & Valued but in an uncivil way - justice as \\
& personal revenge and retribution \\
\hline Solidarity & $\begin{array}{l}\text { Rarely values, no organized opposition, } \\
\text { individualist fight against power }\end{array}$ \\
\hline Equality & Not valued \\
\hline
\end{tabular}




\begin{tabular}{|l|l|}
\hline Public interest & Not valued \\
\hline Independence & Very strongly valued \\
\hline Criticism & Rarely valued \\
\hline Worldly orientation & Valued \\
\hline Altruistic motives & Rarely valued \\
\hline Honesty & Rarely valued, deceit begets success \\
\hline Openness & Rarely valued, vengeance entails secrecy \\
\hline Fairness & Valued \\
\hline Freedom & Strongly valued \\
\hline Liberty & Valued \\
\hline
\end{tabular}

In David Palmer's chapter in this book, he rightly points out that we should avoid going into direct assessment of how well various Chinese actors are conforming to Western norms of liberal democracy (blue code). Of course we can't expect these fantasy online fictions to start following Western values. But even evaluated with Chinese values such as yellow code and red code, they're anti-civil even by Chinese standards. There are these general values at any of the three codes, such as justice, solidarity, public interest and autonomy. But even those general values are also not valued in online fiction. It's anti-civil by any standard.

Judging by content alone, fantasy fiction does not appear to speak to the desire for a more civil society because there is little expression of civil values. However, we need to see this in the Chinese context where the public expression and performance of these ideals and values have been restrained by the non-civil spheres of the Party-state. In the official discourse, there are strong moral and normative elements that ask citizens to love the Party and the country, and 
sacrifice themselves for the general good of the nation. However, people are disillusioned by and weary of this pretentious and empty official discourse. When orthodox moral education is ineffective, a discourse based on the most basic human instincts begins to emerge in popularity and become mainstream. Therefore, the popularity of anti-civil discourse could be a result of official propaganda that emphasizes morality; since it is considered unauthentic, people despise it.

As such, one potential response is to seek authentic expressions and spaces of civil values, probably through various kinds of civil engagement. However, this is very challenging and risky; most people have not come across the opportunity or affinity for such kinds of potentially civil engagement. Also, this requires effort, at least far more than reading online fiction. The other response is to fully reject civil ideals as fake and unauthentic, and pursue nihilistic narcissism. However, if this is actually the case, many social norms would be violated and therefore infeasible. Most people simply do not have the power and ability to solely rely on their own personal strength, disregard others, etc. Yet this sense of freedom and liberty based on the denial of morality and sentiments can be pursued with little effort in fantasy fiction. In that sense, the imaginary world of online fiction becomes the anti-civil mirror image of the corrupted civil ideals of society.

Therefore, Chinese online fiction readers are responding to and rejecting the high moral values as promoted by the state because they feel that these moral values are not being expressed in society. In so doing, they created a shadow civil sphere. It's an anti-civil dark opposition of the appropriation of civil values by the authoritarian regime. The strong imposition of these strong red codes actually has the effect of people faced with the kind of insincere or ritualistic 
performance of those civil values in public, so then they go into an opposite private anti-civil world.

However, this type of cynical, hyper-selfish imagination could actually be a critique of the corrupted civil values in society. The interviewees have a keen sense of the anti-civil qualities of contemporary Chinese society. In fact, they view their online fantasy experiences as an antidote to their sense of injustice, inequality, subjection, and deprivation. They are eager to be part of a society that is fair and based on merit, and their critiques are fueled by the injustices of the real world with obstacles to upward mobility and distrust of the system. Therefore, the seemingly uncivil fiction can be regarded as a vital form of collective consciousness against the current social order, even though this resistance usually takes the implicit and passive form of uncivil escapism drawing on anti-civil values.

That is the other meaning of the shadow civil sphere: in the shadows people are still expressing these moral ideals, but through cynicism. Readers and writers of online fiction are not trying to advocate an even higher level of civility as a corrective because the Party has already claimed absolute civility. Rather, they've created a fantasy world that's even more nasty and brutish. The more anti-civil their resistance is, the more they reflect the frustration of having the civil values they actually believe in go unrealized.

Last but not least, we should also remember that this kind of anti-civil online fiction doesn't represent all fantasy fiction in China. There is yet another realm of fantasy fiction that provides a more civil alternative vision while still grappling with the deep contradictions that restrict the possibility of an "actually existing civil sphere" in China today. For example, The Three-Body Problem, the runaway bestselling science fiction work by Cixin Liu, offers an 
ethical form of resistance to the shortcomings of the capitalist world order that China has embraced since the economic reform. In addition to strong criticism, Liu's stories also articulate hope for a more just social order (Hua 2015; Thieret 2015). Similarly, Song Han, another prominent science fiction writer, also strongly criticizes the long history of institutional and cultural tyranny in China. The work deeply reflects on the myth of development and cautions against unbridled economic and technological development (Song 2013). The awakening of selfconsciousness and emphasis on human agency and autonomy remind us of the enlightenment awakening in China that can be traced back to the May $4^{\text {th }}$ movement. These authors offer alternatives to the dominating anti-civil fiction. Even though their work is not produced nor circulated through the literary websites and therefore not considered as online fiction, their popularity shows that there are alternatives and civil values do appeal to a large audience in China.

Moreover, even among online fiction, there are some "atypical" works that propose civil values and discuss the possibility of straying from the usual paths of a dog-eat-dog world and begin to explore moral possibilities. For example, online writer Mao Ni embraces morality, justice and equality. While writers like Mao Ni do not attract the most readers, they are still quite influential, with devoted and loyal readers, who are generally considered to be "elite" (bettereducated, etc.) (Shao 2016). For example, one strong advocate of Mao Ni's work is a professor at Peking University. ${ }^{18}$ She believes Mao Ni's work engages more with enlightenment values (blue codes). Those followers are usually more educated and at least culturally elite. To them, there are more institutionalized means for advancing civility and far more spaces to express different ideas than the migrant workers or the ordinary persons (who typically read anti-civil fictions). So,

\footnotetext{
${ }^{18} \mathrm{https}: / /$ kknews.cc/zh-hk/culture/jyzbrq.html
} 
there is a relationship between the level of cynicism and the level of social class and cultural capital. The existence of such elite fantasy readers shows that even though the literary websites are dominated by anti-civil fantasy fiction, there are both readers and writers who are seeking alternatives.

\section{Conclusion}

Chinese online fiction and the virtual communities on literary websites constitute an important case where the formation, characteristics and limitations of the subjective civil sphere in China are found. Chinese literary websites are an outlet and a form of compensation for those who live under an authoritarian state with a rapidly growing market economy, where hardly any institutionally autonomous civil sphere in exists, at least by Western standards. The world of online fiction reflects the experience of readers of a non-civil, Hobbesian social life in the real world, and their rejection of their own experience of uncivility, but, lacking any experience of an alternative, and rejecting the moral discourse and civility propagated by the "red code", the only escape is the fantasy of becoming a superhuman in the Hobbesian game, practicing revenge against others through a narcissistic, retributive means of justice.

As such, the online fiction fantasy world becomes a shadow civil sphere. Writers and readers resist expressing greater civility, and instead cultivate extremely anti-civil behavior and allow cynicism to flourish. This kind of cynicism and alienation leads to a revision of the Confucian code in an increasingly anti-civil way.

Even though online fiction serves as a means of escape, to some extent, it is a means of resistance too. With little chances of public engagement and expression, and social justice difficult to achieve in reality, Chinese users of literary websites have created meritocratic fantasy 
worlds online that operate on certain principles of justice. These compensate for their experienced lack of power and control in the real world. Even though these fictional worlds are largely anti-civil, their eminence reflects the disappointment users have with reality and their desire for an ideal society. Yet even this imaginary society has limitations and abides by the established framework, so it is uncertain if real civil values could emerge from the discussion that surrounds online fiction. Thus, the civil spirit cannot be taken for granted. Without institutional supports, educational or communicative institutions to cultivate civil values, and no cultural resources for reference, people may be unhappy about the corrupted civil values and yearn for justice and equality, but do not have idiopathic civil values or the desire for a more democratic society. Online congregations do not necessarily lead to the emergence of a civil spirit, at least not one that is fully-fledged. Instead, perception, including imagination, is influenced by traditional culture, historical memory and current social conditions.

While the implications seem bleak and hopeless, moral cynicism actually could imply high moral values. Even with few cultural sources for a democratic life, yearning persists for justice and equality, driven by the fundamental instinct for dignity in response to the oppression and frustrations of living in a non-civil society. I echo here that the pursuit for justice and solidarity is universal per Alexander (2006).

The point is that people lack a coherent sense of moral selfhood. In post-Mao China, people react against the sacrificial discourse of communist morality by discovering and even affirming selfishness, which has resulted in a "divided self", torn between conflicting moral and anti-moral visions (Kleinmans 2011). People have this yearning for the positive civil values, but they also have selfishness and an anti-civil side. Thus, the exploration and indulgence in highly anti-civil fantasies through online fiction do not necessarily imply either the lack of moral sense 
or adherence to civil values. Rather, these online fiction fantasies imply that civil values do not emerge in a vacuum, but need to be nurtured in real life and experienced.

\section{References:}

Alexander, Jeffrey. 2015. "Nine Theses on The Civil Sphere." In P. Kivisto and G. Sciortino, eds., Solidarity, Justice, and Incorporation: Thinking through The Civil Sphere. New York: Oxford University Press, pp. 172-190.

Alexander, Jeffrey C. 2006. The civil sphere. New York: Oxford University Press.

Bootz, Philippe. 2011. "Regarding Digital Literature." Caietele Echinox 20, 79-96.

CNNIC. 2010. Report on users of online Chinese literature, China Internet Network Information Center. 2010-12.

CNNIC. (2017). Report on Di 40 Ci Zhongguo Hu Lian Wang Luo Fa Zhan Bao Gao (The $40^{\text {th }}$ report on the development of Internet in China), China Internet Network Information Center.

Cui, Z. 2011. Zhong Guo Wang Luo Wen Xue De Kun Jing Yu Shou Huo (The conditions of online literature in China). Unpublished Doctoral Thesis, Peking University, Beijing.

Feilitzen, Cecilia and Linné, Olga. 1975. "Identifying with television characters." Journal of Communication 25.4 (4), 51-55.

Frye, Northrop. 1973. Anatomy of Criticism. Princeton University Press.

Griswold, Wendy. 1993. "Recent moves in the sociology of literature." Annual review of sociology $19,455-467$.

Hill, Sarah E., Christopher D. Rodeheffer, Vladas Griskevicius, Kristina Durante and Andrew 
Edward White. 2012. "Boosting beauty in an economic decline: mating, spending, and the lipstick effect." Journal of personality and social psychology 103, no. 2: 275.

Hirschman, Elizabeth C. 1983. "Predictors of self-projection, fantasy fulfillment, and escapism." The Journal of Social Psychology 120, no. 1: 63-76.

Hobbes, Thomas. [1651](1994). Leviathan, MA: Hackett Publishing.

Khoshrokovar, Farhad. 2015. "The Civil Sphere and the Arab Spring." In P. Kivisto and G. Sciortino, eds., Solidarity, Justice, and Incorporation: Thinking through The Civil Sphere. New York: Oxford University Press, pp. 142-171.

Kleinman, Arthur. 2011. "The divided self, hidden values, and moral sensibility in medicine.” The Lancet 377(9768): 804-805.

Lee, Ching Kwan and Yonghong Zhang. 2013. "The Power of Instability: Unraveling the Microfoundations of Bargained Authoritarianism in China. "American Journal of Sociology, 118, No. 6, pp. 1475-1508.

Li, Hua. 2015. "The Political Imagination in Liu Cixin's Critical Utopia: China 2185." Science Fiction Studies, 42(3), 519-540.

Li, L. 2012. Wen Bian Ran Hu Shi Qing-Zhuan Xing Zhong Huo De Wang Luo Wen Xue (Online Literature in China in Transition). Unpublished Master's Thesis, Graduate School of Chinese Academy of Social Sciences, Beijing.

Ngai, Sianne. 2007. Ugly Feelings. Cambridge: Harvard University Press.

Rau, Anja. 2001. Wreader's Digest: How To Appreciate Hyperfiction. Journal of Digital Information, 1(7). Retrieved June 2014 
(http://journals.tdl.org/jodi/index.php/jodi/article/view/28/29).

Ren, Xiang and Lucy Montgomery. 2012. "Chinese online literature: creative consumers and evolving business models." Arts Marketing: an international journal 2, no. 2: 118-130.

Ryan, Marie-Laure. 2011. "The interactive onion: Layers of user participation in digital narrative texts." In R. Page and B. Thomas, eds., New Narratives: Stories and storytelling in the digital age. Lincoln, Nebraska: University of Nebraska Press, pp. 35-62.

Shao, Yanjun. 2016. Heuristics of Classic Chinese Online Fictions(Wang luo wen xue jing dian jie du). Beijing: Peking University Press.

Sianne, N. G. A. I. 2007. Ugly feelings. Harvard University Press.

Song, Mingwei. 2013. "Variations on Utopia in Contemporary Chinese Science Fiction." Science Fiction Studies , 40(1), 86-102.

Thieret, Adrian. (2015). Society and utopia in liu cixin. China Perspectives, (1), 33-39.

Tian, Xiaoli and Michael Adorjan. 2016. "Fandom and coercive empowerment: the commissioned production of Chinese online literature." Media, Culture \& Society, 38(6), 881-900.

Tian, Xiaoli. 2016. Parasocial interaction in the internet era: a sociological analysis of online literature in China. Journal of Tsinghua University (Philosophy and Social Sciences), 31(1), 173181.

Torres, Rui. 2005. Digital poetry and collaborative wreadings of literary texts. Retrieved June 2014 (http://www.telepoesis.net/papers/dpoetry.pdf).

Yang, Guobin. 2008. "Chinese Internet literature and the changing field of print culture." In C. 
Brokaw and C. A. Reed, eds., From woodblocks to the Internet: Chinese publishing and print culture in transition, circa: 333-352. 